\title{
Sulfonylurea-Induced Hypoglycemia in a Patient With Cirrhosis
}

\author{
Corey Braet ${ }^{1}$, Yasmine Hussein Agha ${ }^{1}$, Ali Taleb ${ }^{1}$, Charles Buess ${ }^{1}$, John Millard ${ }^{2}$ \\ 1. Internal Medicine, University of Kansas School of Medicine-Wichita, Wichita, USA 2. Pharmacy, Robert J. Dole \\ Veterans Affairs Medical Center, Wichita, USA
}

Corresponding author: Yasmine Hussein Agha, yhusseinagha@kumc.edu

\begin{abstract}
Type 2 diabetes mellitus is highly prevalent among patients with cirrhosis. The pharmacological management of this disease in patients with chronic liver disease remains controversial, however. Insulin secretagogues such as sulfonylureas are associated with a high risk of hypoglycemia among diabetics. In patients with cirrhosis, this risk is more pronounced due to decreased hepatic clearance, concurrent alcoholism, hypoalbuminemia, and acute liver decompensation. In this case report, we present a case of severe refractory hypoglycemia secondary to glipizide in a patient with alcoholic cirrhosis. We believe that the use of sulfonylureas in this patient population should be contraindicated to avoid debilitating neurologic damage and death following hypoglycemia.
\end{abstract}

Categories: Endocrinology/Diabetes/Metabolism, Internal Medicine, Gastroenterology

Keywords: sulfonylurea compounds, liver cirrhosis, drug contraindications

\section{Introduction}

Type 2 diabetes mellitus (DM) is highly associated with chronic liver disease, with an overall prevalence estimated at $31 \%$ among patients with cirrhosis [1]. Treating DM with sulfonylureas (SUs) in patients with cirrhosis is challenging since these drugs are metabolized by the liver. Most guidelines consider SUs safe in this patient population, whereas others recommend dose reduction $[2,3]$. The extent of liver damage in patients with cirrhosis is unpredictable and difficult to quantify, whether the patient is in a compensated state or deteriorating. With that in mind, the risk of hypoglycemia is expected to be higher in patients with cirrhosis taking SUs compared with diabetics without liver disease taking SUs. Despite the debilitating and fatal outcomes of hypoglycemia, no guidelines have discussed contraindicating SUs in patients with chronic liver disease. We present a case of severe refractory hypoglycemia secondary to glipizide in a patient with alcoholic cirrhosis.

Received 05/25/2020 Review began 06/01/2020 Review ended 06/02/2020 Published 06/08/2020

(c) Copyright 2020 Braet et al. This is an open access article distributed under the terms of the Creative Commons Attribution License CC-BY 4.0., which permits unrestricted use, distribution, and reproduction in any medium, provided the original author and source are credited.

\section{Case Presentation}

A 69-year-old male with a history of alcoholic liver cirrhosis and DM presented to the emergency department with weakness since awakening that morning. He was conscious but lethargic and was not oriented to time or place. Neurological examination was unremarkable for focal neurological deficits other than mild slurring of his speech. He denied having any seizure activity or loss of consciousness prior to arrival. His last alcoholic drink was three days prior to presentation. On physical examination, he had icterus, was mildly jaundiced, and appeared malnourished. He had minimal ascites and mild bilateral nonpitting lower limb edema. His lungs were clear, heart sounds were normal, and abdomen was non-tender.

He was afebrile, tachycardic with a heart rate of 120 beats per minute, and normotensive. Serum glucose was measured at bedside and was profoundly low ( $40 \mathrm{mg} / \mathrm{dL}$ ). He was initially managed with multiple boluses of $50 \%$ dextrose, glucose gel every 15 minutes, and a continuous infusion of $10 \%$ dextrose in water in a stepwise manner. However, his blood sugar failed to stabilize. Initial laboratory work-up revealed leukocytosis, thrombocytopenia, acute kidney injury, hypoalbuminemia, transaminitis, and hyperbilirubinemia (Table 1). His serum ethanol was undetectable, and urine drug screen was negative. Urine SU screen was ordered as well and was still pending on the first day of admission. His MELDNa score (Model for End-stage Liver Disease with Sodium) was 25, which translated to a 15\% chance of mortality within three months. His liver function test and MELD-Na score obtained six months prior to admission were similar to his current results. 


\section{Cureus}

\begin{tabular}{|c|c|c|}
\hline Laboratory tests & Results & Reference range \\
\hline White blood cell count & 18.9 & $4.8-10.8 \times 10^{3} / \mu \mathrm{L}$ \\
\hline Hemoglobin & 12 & $12-16 \mathrm{gm} / \mathrm{dL}$ \\
\hline Platelets & 100 & $150-400 \times 10^{3} / \mu \mathrm{L}$ \\
\hline Sodium & 135 & $136-145 \mathrm{meq} / \mathrm{L}$ \\
\hline Potassium & 4.5 & 3.5-5.1 meq/L \\
\hline Chloride & 102 & 96-106 meq/L \\
\hline Bicarbonate & 26 & $23-29 \mathrm{meq} / \mathrm{L}$ \\
\hline Blood urea nitrogen & 28 & $6-20 \mathrm{mg} / \mathrm{dL}$ \\
\hline Creatinine & 1.85 & $0.6-1.3 \mathrm{mg} / \mathrm{dL}$ \\
\hline Albumin & 1.5 & $3.5-5.5 \mathrm{~g} / \mathrm{dL}$ \\
\hline Aspartate aminotransferase & 152 & $10-40 \mathrm{U} / \mathrm{L}$ \\
\hline Alanine aminotransferase & 86 & $10-40 \mathrm{U} / \mathrm{L}$ \\
\hline Alkaline phosphatase & 95 & $30-120 \mathrm{U} / \mathrm{L}$ \\
\hline Total bilirubin & 5.5 & $0.3-1.0 \mathrm{mg} / \mathrm{dL}$ \\
\hline Unconjugated bilirubin & 4 & $0.2-0.7 \mathrm{mg} / \mathrm{dL}$ \\
\hline International normalized ratio & 1.5 & $0.8-1.1$ \\
\hline Ammonia & 30 & $40-70 \mu \mathrm{g} / \mathrm{dL}$ \\
\hline Ethanol & $<5$ & $5 \mathrm{mg} / \mathrm{dL}$ \\
\hline
\end{tabular}

TABLE 1: Initial laboratory work-up

Computed tomography (CT) of the brain without contrast did not show any acute abnormalities. Upon review of his medication list, it was noted that he was on glipizide for the treatment of DM, and his last dose was the night prior to presentation. He had been on this medication for years and had never developed hypoglycemia. Since SU toxicity was the most probable cause of his persistent hypoglycemia, he was given $50 \mathrm{mcg}$ of octreotide subcutaneously every eight hours in addition to a continuous infusion of $5 \%$ dextrose in half normal saline until serum glucose increased and was maintained within the normal range. Three days later, his urine SU screen showed a urine glipizide level of $480 \mathrm{ng} / \mathrm{mL}$ (reference: $<5 \mathrm{ng} / \mathrm{mL}$ ).

\section{Discussion}

Glucose intolerance and DM are highly prevalent among patients with cirrhosis [4]. Studies have shown that glucose intolerance is found in $80 \%$ of patients with cirrhosis, whereas the prevalence of overt DM was found to range from $10 \%$ to $30 \%[4,5]$. This has been reported to be caused by increased insulin resistance in patients with cirrhosis [2]. This association is even more pronounced in patients with alcoholic liver disease given the propensity of alcohol ingestion to decrease insulin-mediated glucose uptake in addition to chronic pancreatic damage $[5,6]$.

Pharmacological management of DM in patients with chronic liver disease is still controversial. Due to increased risk of lactic acidosis, metformin is not recommended as a first-line treatment for DM in patients with cirrhosis [2]. Insulin secretagogues such as SUs, which are used as second-line treatment of DM in the general population, are generally considered safe in patients with liver disease, although issues regarding their efficacy have been raised in the setting of alcoholic liver disease and pancreatic damage [2]. In particular, patients with decompensated cirrhosis are more prone to hypoglycemia and have shown a decreased capacity to counteract hypoglycemia secondary to these medications [2,7]. Since SUs are metabolized by the liver, a decrease in breakdown of these medications in the setting of liver cirrhosis may result in increased plasma concentrations, thereby increasing the risk of hypoglycemia [7].

Additionally, hypoalbuminemia in the setting of chronic liver disease may result in reduced protein-binding of SUs, which may also result in increased SU plasma concentrations, thereby increasing the risk of 
hypoglycemia $[3,8]$. In the setting of alcohol consumption, decreased potency of SUs may result from alcohol-induced enzymatic degradation of SUs in addition to damage of beta islet cells of the pancreas $[9,10]$. Despite this decreased potency, patients taking SUs who have not abstained from alcohol are at an increased risk of hypoglycemia due to the inhibitory effects of alcohol on hepatic gluconeogenesis [7]. Another contributory factor to hypoglycemia is the increased prevalence of malnutrition among patients with chronic liver disease and patients with chronic alcohol use [3,7].

Given the limited studies evaluating the pharmacokinetics and safety of oral anti-diabetic drugs in patients with cirrhosis, the use of SUs remains a controversial issue. The American Diabetes Association (ADA) and the European Association for the Study of Diabetes (EASD) stated that it is "unwise to use sulfonylureas, particularly glyburide" in the setting of severe hepatic disease due to the risk of hypoglycemia [11]. Khan et al. reported the dosage of SUs should be decreased to half of the usual dosage in patients with cirrhosis, particularly if they have not abstained from alcohol [12]. Scheen et al. explained that SUs can be given with close monitoring for hypoglycemia [7]. Gangopadhyay and Singh reported that while SUs should be avoided in patients with cirrhosis, lower doses may be considered in patients with Child-Pugh Class A and B and should be completely avoided in patients with Child-Pugh Class C [3].

The patient described in this case report had a longstanding history of alcoholic cirrhosis, was still drinking alcohol intermittently, and was on glyburide. He developed hypoglycemia after stopping drinking alcoholic beverages for three days, which may have allowed glipizide to be more potent since its alcohol-induced enzymatic degradation was reduced. Patients with medication non-compliance, alcoholism, malnutrition, and recurrent hospital admissions have unpredictable outcomes regardless of whether their liver disease is decompensated or stable. Given the high risk of death and long-term neurological damage from hypoglycemia, we believe that SUs should be contraindicated in patients with chronic liver disease.

\section{Conclusions}

The risk of hypoglycemia secondary to SUs in patients with cirrhosis is more likely to be higher than the general diabetic population due to associated behavior such as alcoholism, malnutrition, medication interaction, decreased hepatic clearance, and further decompensation. The use of SUs in this patient population should be contraindicated to avoid further decompensation and death following hypoglycemia.

\section{Additional Information}

\section{Disclosures}

Human subjects: Consent was obtained by all participants in this study. Conflicts of interest: In compliance with the ICMJE uniform disclosure form, all authors declare the following: Payment/services info: All authors have declared that no financial support was received from any organization for the submitted work. Financial relationships: All authors have declared that they have no financial relationships at present or within the previous three years with any organizations that might have an interest in the submitted work. Other relationships: All authors have declared that there are no other relationships or activities that could appear to have influenced the submitted work.

\section{References}

1. Lee WG, Wells CI, McCall JL, Murphy R, Plank LD: Prevalence of diabetes in liver cirrhosis: a systematic review and meta-analysis. Diabetes Metab Res Rev. 2019, 35:3157. 10.1002/dmrr.3157

2. Tolman KG, Fonseca V, Dalpiaz A, Tan MH: Spectrum of liver disease in type 2 diabetes and management of patients with diabetes and liver disease. Diabetes Care. 2007, 30:734-743. 10.2337/dc06-1539

3. Gangopadhyay KK, Singh P: Consensus statement on dose modifications of antidiabetic agents in patients with hepatic impairment. Indian J Endocrinol Metab. 2017, 21:341-354. 10.4103/ijem.IJEM_512_16

4. Zein NN, Abdulkarim AS, Wiesner RH, Egan KS, Persing DH: Prevalence of diabetes mellitus in patients with end-stage liver cirrhosis due to hepatitis C, alcohol, or cholestatic disease. J Hepatol. 2000, 32:209-217. 10.1016/s0168-8278(00)80065-3

5. Garcia-Compean D, Jaquez-Quintana JO, Gonzalez-Gonzalez JA, Maldonado-Garza H: Liver cirrhosis and diabetes: risk factors, pathophysiology, clinical implications and management. World J Gastroenterol. 2009, 21:280-288. 10.3748/wig.15.280

6. Hickman IJ, Macdonald GA: Impact of diabetes on the severity of liver disease . Am J Med. 2007, 120:829834. 10.1016/j.amjmed.2007.03.025

7. Scheen AJ: Pharmacokinetic and toxicological considerations for the treatment of diabetes in patients with liver disease. Expert Opin Drug Metab Toxicol. 2014, 10:839-857. 10.1517/17425255.2014.902444

8. Kalra S, Aamir AH, Raza A, et al.: Place of sulfonylureas in the management of type 2 diabetes mellitus in South Asia: a consensus statement. Indian J Endocrinol Metab. 2015, 19:577-596. 10.4103/2230-8210.163171

9. Papazafiropoulou A, Melidonis A: Antidiabetic agents in patients with hepatic impairment. World J MetaAnal. 2019, 7:380-388. 10.13105/wjma.v7.i8.380

10. Bryan J, Crane A, Vila-Carriles WH, Babenko AP, Aguilar-Bryan L: Insulin secretagogues, sulfonylurea receptors and K(ATP) channels. Curr Pharm Des. 2005, 11:2699-2716. 10.2174/1381612054546879

11. Davies MJ, D'Alessio DA, Fradkin J, et al.: Management of hyperglycemia in type 2 diabetes, 2018. A Consensus Report by the American Diabetes Association (ADA) and the European Association for the Study of Diabetes (EASD). Diabetes. 2018, 41:2669-2701. 10.2337/dci18-0033 


\section{Cureus}

12. Khan R, Foster GR, Chowdhury TA: Managing diabetes in patients with chronic liver disease . Postgrad Med. 2012, 124:130-137. 10.3810/pgm.2012.07.2574 